\title{
Effect of incorporating fat into a liquid test meal on the relation between intragastric distribution and gastric emptying in human volunteers
}

\author{
L A Houghton, Y F Mangnall, N W Read
}

\begin{abstract}
The relation between gastric emptying and the intragastric distribution of $300 \mathrm{ml}$ radiolabelled beef consommé with and without $60 \mathrm{~g}$ margarine was investigated by performing randomised, paired gammacamera studies in seven healthy male volunteers (aged 20-22 years). The low calorie bland meal emptied rapidly from both the proximal and distal stomach after a short lag period (4-6 min), during which $24-50 \%$ of the liquid passed into the distal stomach. Addition of margarine to the liquid test meal increased the lag period (median $32 \mathrm{~min}$, range $7-60 \mathrm{~min} ; \mathrm{p}<0.01$ ) and decreased the slope of emptying ( $T^{1 / 2}$ lag period $88 \mathrm{~min}, 49-146 \mathrm{~min} v 15 \mathrm{~min}, 10-57$. min; $\mathbf{p}<0.01$ ). During the lag period there was an initial filling of the distal stomach, similar to that with the bland liquid, followed by a redistribution of between $19 \%$ and $61 \%$ (median $46 \%$ ) of the distal stomach contents back into the proximal stomach. At the onset of emptying, the distal stomach filled (median $30 \%$, range $16-34 \%$ ) and during this time the proximal stomach emptied twice as fast as the whole stomach $(p<0.05)$. Thereafter, the distal stomach capacity remained relatively constant while both the proximal and whole stomach emptied at similar rates. This study shows that the delay in gastric emptying of a liquid that has a high fat content is due in part to a redistribution of distal stomach contents back into the proximal stomach.
\end{abstract}

It is generally thought that contraction of the gastric fundus is responsible for the emptying of liquids from the stomach, whereas antral contractions control the emptying of solids. ${ }^{12}$ The evidence for the predominant role of the fundus in the emptying of liquids from the stomach comes from the results of surgical operations. Resection of the fundus ${ }^{3}$ or vagal denervation of the proximal stomach ${ }^{4}$ in the dog increases activity, ${ }^{8-10}$ and relaxation of the fundus. ${ }^{511}$ The importance, however, of each of these components in the emptying of liquid meals of high and low lipid content is unclear.

This study attempts to elucidate the relative roles of the proximal and distal stomach in retarding gastric emptying of liquid meals of high lipid content by analysing the distribution of radioactive counts in the proximal and distal stomach.

\section{Methods}

\section{SUBJECTS}

Paired studies were carried out in seven healthy male volunteers, aged 20 to 22 years. All subjects gave their fully informed consent for the study to be carried out.

The equipment used conformed to the safety standards laid down by the Department of Health and the study was carried out in accordance with the Declaration of Helsinki and with the approval of the Ethical Sub-Committee of the Sheffield Southern District Hospitals.

\section{EXPERIMENTAL PROTOCOL}

The subjects were studied on two separate occasions. On one occasion they drank $300 \mathrm{ml}$ of beef consommé (Beef Consomme, Campbell Grocery Products, King's Lynn, Norfolk, containing $0.6 \mathrm{~g}$ carbohydrate, $2 \cdot 1 \mathrm{~g}$ protein) labelled with $2 \mathrm{MBq}{ }^{99 m}$ Technetium-Tin Colloid (Amersham International, Buckinghamshire). On the second occasion they drank an equivalent volume of radiolabelled consommé to which had been added $60 \mathrm{~g}$ (455 kcal) margarine (SUMA Sunflower Margarine, Halifax, West Yorks). These soups have been used in previous studies and are very appetising. The order of the studies was randomised.

The subjects fasted for at least 12 hours before each study. No alcohol was permitted for 24 hours before each study and cigarette smoking was not allowed. On the day of the study the subject sat vertically against a posteriorly positioned gammacamera (Model $1201 \mathrm{Pho} /$ Gamma Scintillation Camera, Nuclear-Chicago, Europa NV, Amsterdam, The Netherlands). The subject then drank the soup within one minute.

Images of the distribution of the radioactivity in the abdominal cavity were collected over consecutive two minute periods for the first 45 frames and then over consecutive five minute periods for a further 18 frames. The total period of data collection was 180 minutes. Data collection began at the start of liquid ingestion. At the \footnotetext{
intragastric pressure and hastens the emptying of liquid meals. In the intact stomach fundic tone is greater during the emptying of saline liquid test meals than liquid test meals that contain a high proportion of fat, ${ }^{5}$ but a pressure gradient between the stomach and duodenum has never been shown. Manometric and scintigraphic observations in humans and dogs suggest that bland liquids empty in gushes associated with coordinated contractions of the antrum and duodenum. ${ }^{67}$ Moreover, when gastric emptying is delayed by increasing the fat content of a liquid there is suppression of antral contractions, ${ }^{89}$

enhancement of phasic and tonic pyloric

Correspondence to:

Dr L A Houghton, Sub-Dep of Gastrointestinal Physiology Sheffield, Royal Hallamshire Hospital, Sheffield S10 2JF.

Accepted for publication

18 December 1989

Sub-Department

Physiology and Nut

Surgery, University

S10 2JF

L A Houghton

Y F Mangnal
} 


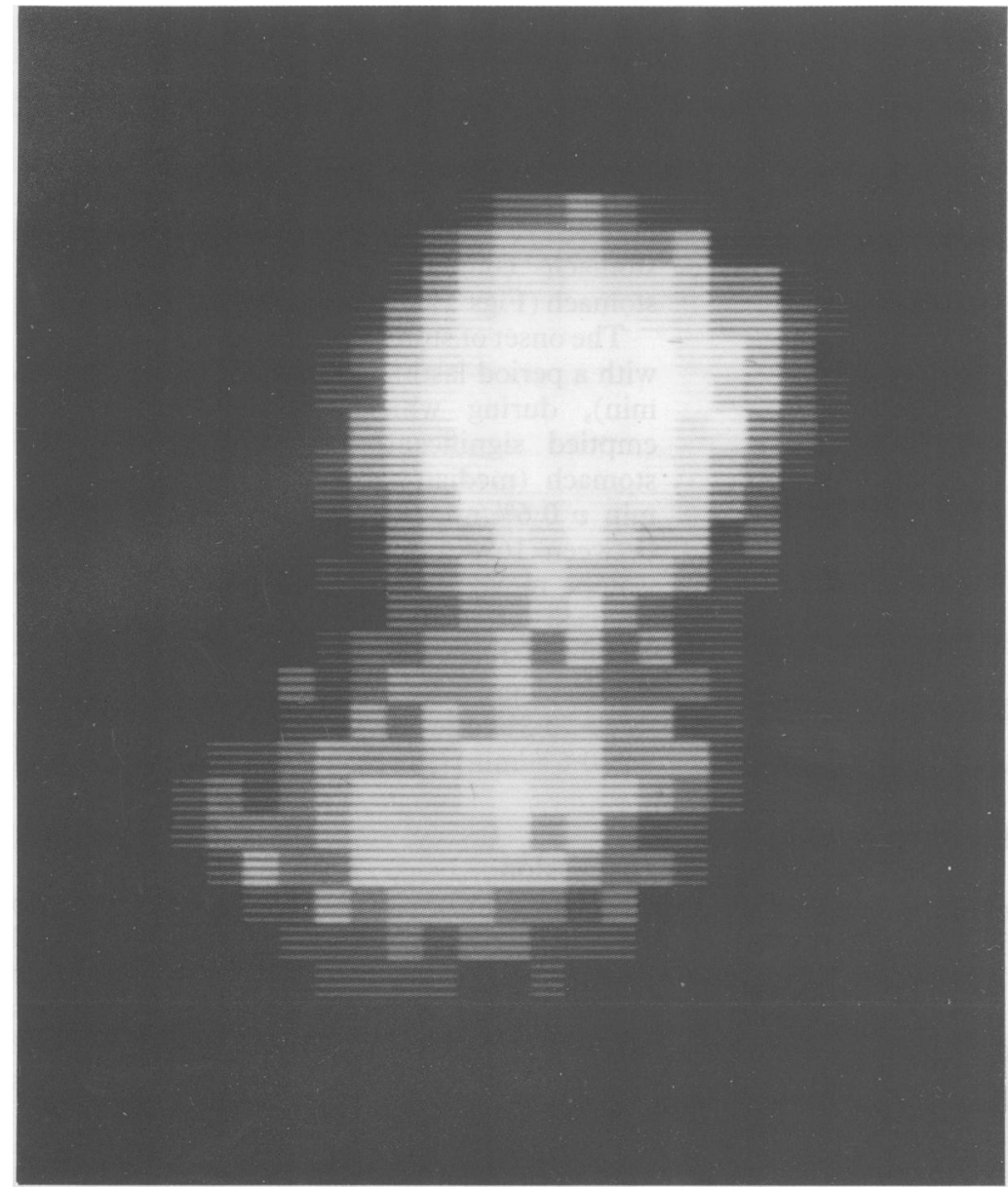

Figure 1: A scintiphotograph showing the distribution of liquid in the stomach. Note that the proximal and distal regions of the stomach can easily be recognised as two regions of intense

radioactivity separated by $a$ fainter band of radioactivity. end of the study a further $2 \mathrm{MBq}{ }^{99 \mathrm{~m}} \mathrm{Tc}$-Tin Colloid in $150 \mathrm{ml}$ water was given orally and a left lateral image of the stomach was acquired over five minutes so that the images of the stomach, obtained by the posteriorly placed gammacamera, could be corrected for attenuation caused by the isotope moving away from the gammacamera as the meal emptied. ${ }^{1213}$

\section{ANALYSIS OF THE GAMMACAMERA RECORDS}

The position of the stomach was identified from the images obtained during the first 10 minutes of the study and outlined using a cursor. Subareas were also defined to enclose the proximal (fundus) and distal (antrum) regions of the stomach. These could easily be recognised as two regions of intense radioactivity separated by a fainter band of radioactivity (Fig 1). The computer then extracted the counts from each region of interest, corrected them for decay and tissue attenuation, and expressed them as a percentage of the counts obtained in the gastric region immediately after ingestion of the meal. These figures were used to construct profiles of the proportion of counts in the whole stomach and in each subregion throughout the study. The profiles of emptying were then analysed to yield values for: $(a)$ the period before $10 \%$ of the isotope had emptied from the stomach (lag period); (b) the time from the onset of emptying to the point at which $50 \%$ of the isotope had left the stomach ( $\mathrm{T}^{1} / 2$ lag period); (c) the rate of emptying from the proximal, distal, and whole stomach, obtained by drawing a tangent to the
Effect of increasing the calorie content on the emptying of a liquid meal from the stomach

\begin{tabular}{lcll}
\hline & $\begin{array}{l}\text { Consommé } \\
\text { without } \\
\text { margarine }\end{array}$ & $\begin{array}{l}\text { Consommé } \\
\text { with } \\
\text { margarine }\end{array}$ & $p$ \\
\hline $\begin{array}{l}\text { Lag period (min) } \\
\begin{array}{l}\text { Emptying phase } \\
\left(\mathrm{T}^{1 / 2} \text { lag period) }\right.\end{array}\end{array}$ & $4(4-6)$ & $32(7-60)$ & $<0.01$ \\
\hline
\end{tabular}

Data expressed as median and range.

emptying curves. Finally, any initial emptying of the liquid that occurred during ingestion was quantified by measuring the counts outside the gastric region.

\section{STATISTICAL ANALYSIS}

Data were analysed using the Wilcoxon rank sum test.

\section{Results}

\section{BLAND LIQUID}

During ingestion of the bland liquid, $1-3 \%$ of the liquid passed into the duodenum. Gastric emptying then stopped for 4-6 minutes (lag period) (Table) during which time $24-50 \%$ (median $32 \%$ ) of the liquid passed from the proximal to the distal region of the stomach. Thereafter, both the proximal (median $2.93 \% / \mathrm{min}$, range $0.92-4.0 \% / \mathrm{min})$ and distal $(0.68 \% / \mathrm{min}, 0.50$ $1 \cdot 17 \% / \mathrm{min}$ ) stomach emptied rapidly (Fig 2 ).

\section{EFFECT OF ADDITION OF FAT}

Addition of $60 \mathrm{~g}$ margarine to the beef consommé did not affect the amount of liquid that passed

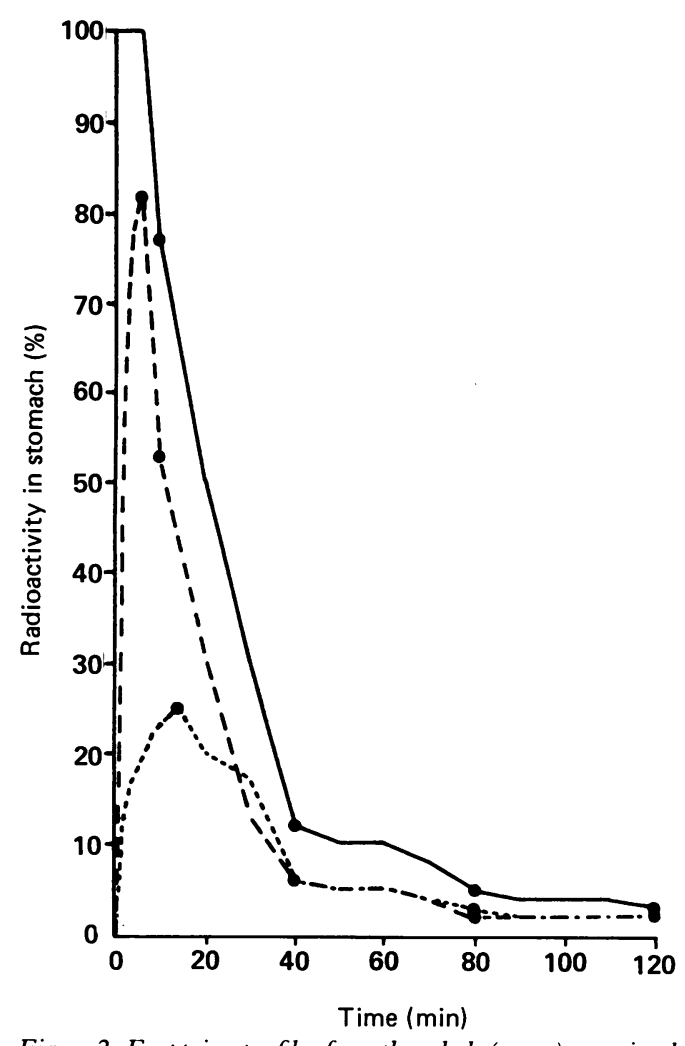

Figure 2: Emptying profiles from the whole (__ ), proximal (.--), and distal (......) stomach for the low calorie bland meal in a typical normal healthy volunteer. 
Figure 3: Emptying profiles from the whole (_proximal ( and distal fat content liquid meal in $a$ typical normal healthy

volunteer. The letters refer

to corresponding

scintiphotographs in

Figure 4. (.....) stomach for the high

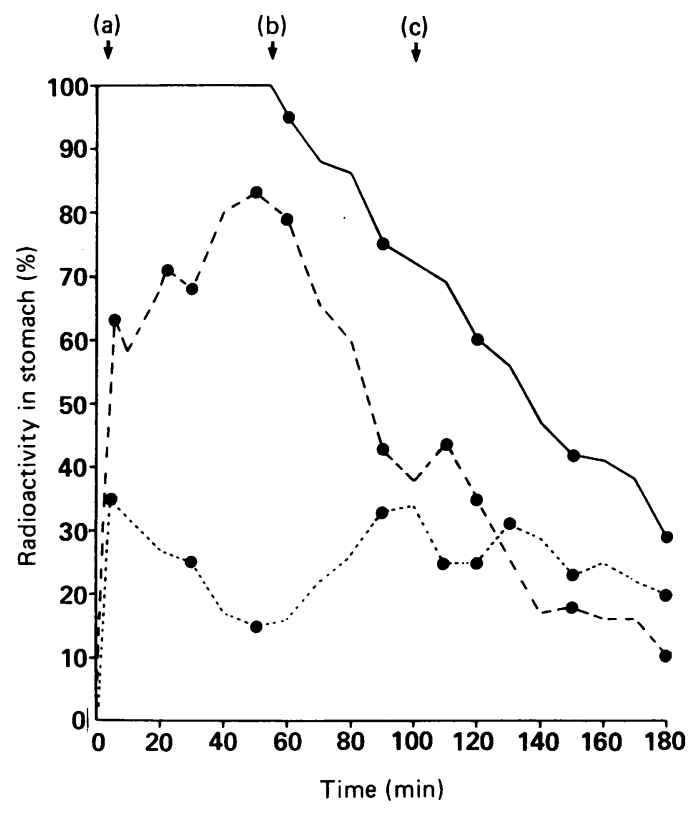

into the duodenum during ingestion, but significantly increased the lag period and decreased the slope of emptying compared with the bland liquid (Table, Fig 3).

During the lag period between $20 \%$ and $36 \%$ Scintiphotographs showing the distribution of the high fat content liquid meal $(A) 4$ $\min ,(B) 54$ min, and $(C)$ 100 min after ingestion in a typical volunteer.
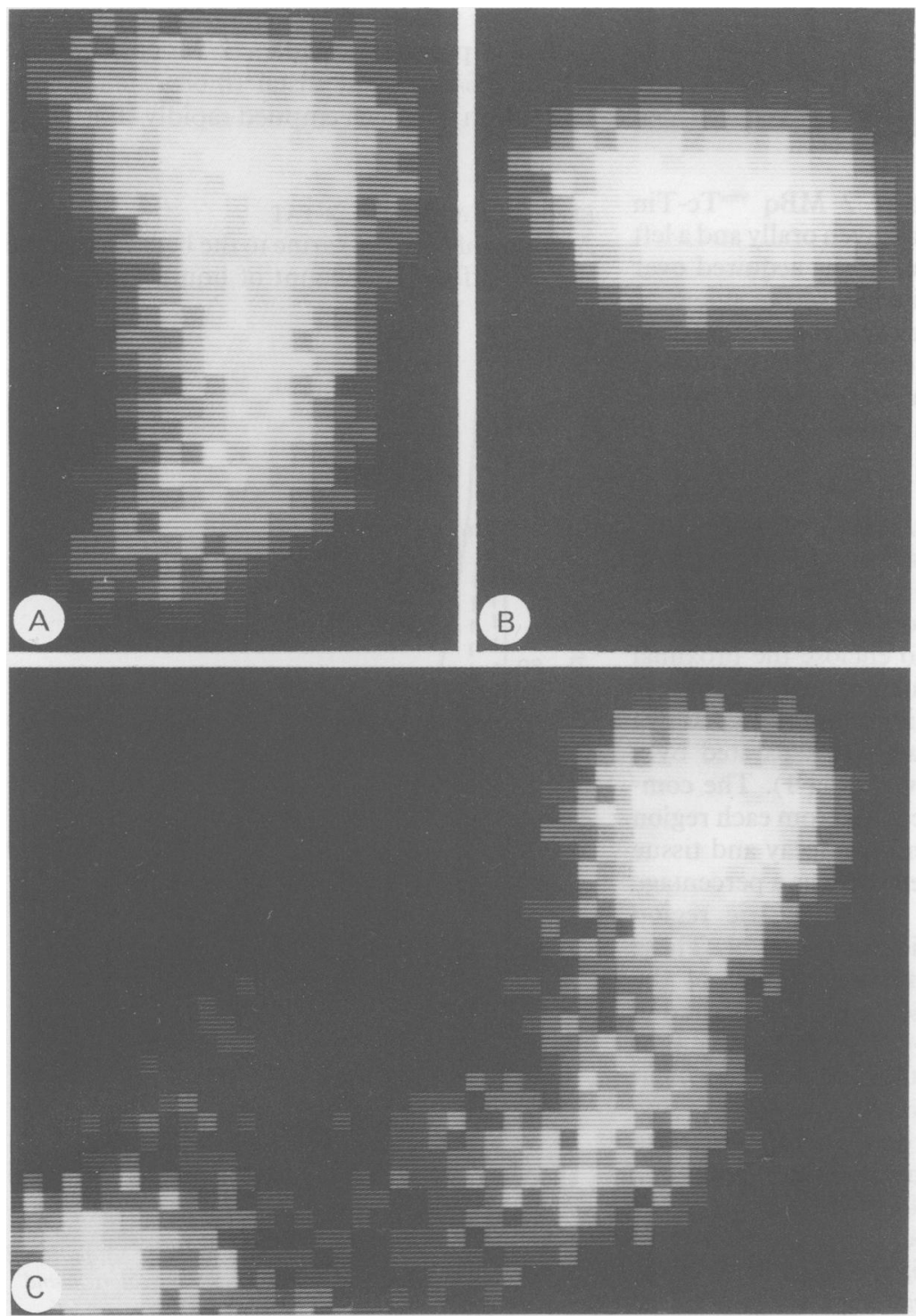

(median 33\%) of the original fluid meal entered the distal stomach between 2 and 10 minutes (median $4 \mathrm{~min}$ ) after ingestion, which was not significantly different from that of the bland liquid. This was then followed by a period of between 24 and $46 \mathrm{~min}$ (median $26 \mathrm{~min}$ ) in which between $19 \%$ and $61 \%$ (median $46 \%$ ) of the distal stomach contents re-entered the proximal stomach (Figs 3 and 4).

The onset of stomach emptying was associated with a period lasting 10-42 minutes (median 36 min), during which the proximal stomach emptied significantly faster than the whole stomach (median $1.3 \% / \mathrm{min}$, range $0.6-1.9 \%$ / $\min v 0.6 \% / \mathrm{min}, 0.4-1.5 \% / \mathrm{min} ; \mathrm{p}<0.05)$ and between $16 \%$ and $34 \%$ (median $30 \%$ ) of the isotope moved from the proximal to the distal stomach. Thereafter, the distal stomach capacity remained relatively constant while both the proximal and whole stomach emptied at similar rates $(0.3 \% / \mathrm{min}, 0.2-0.5 \% / \mathrm{min} v 0.3 \% / \mathrm{min}$, $0 \cdot 2-0 \cdot 6 \% / \mathrm{min})($ Fig 3 ).

\section{Discussion}

This study documents how the addition of fat to a liquid test meal affects the distribution of fluid between the proximal and distal regions of the stomach and attempts to show the relative roles played by the proximal and distal stomach in the emptying of bland liquid meals and liquid meals containing a large amount of lipid.

The bland liquid dispersed quickly throughout the stomach and then emptied rapidly from both the proximal and distal regions of the stomach.

Addition of margarine to the liquid delayed gastric emptying not only by decreasing the slope of emptying but also by increasing the lag period, confirming previous observations with other liquid meals of high nutrient content. ${ }^{12}$ Our observations, however, indicate that the increase in the lag period is related to a redistribution of the liquid back into the proximal stomach. The forces responsible for this redistribution cannot be deduced from this study, but either relaxation of proximal stomach or an increase in antral tone or both would be expected to alter the balance of forces to favour movement of liquid into the fundus.

What triggers the redistribution of liquids of high fat content from the distal to the proximal region of the stomach and increases the lag period? Close examination of the scintigrams shows that a small percentage of the liquid (1$3 \%$ ) passes into the duodenum during ingestion of the liquid. It is known that infusion of lipid into the duodenum causes a redistribution of solid food from the distal to proximal regions of the stomach ${ }^{1+}$ and diminishes proximal stomach tone. ${ }^{51}$ Thus it seems likely that it is the interaction of the lipid with the fat receptors in the duodenum that initiates these events. ${ }^{15}$

At the start of gastric emptying the proximal stomach emptied significantly faster than the whole stomach, resulting in an increase in antral capacity. Thereafter, the rate of emptying from the whole stomach was similar to that of the proximal stomach. These observations favour the hypothesis ${ }^{16}$ that the proximal stomach acts 
to prime the antral pump, maintaining its capacity constant as the fluid emptied into the duodenum.

Our observations suggest that both the proximal and distal regions of the stomach collaborate in the emptying of liquid meals containing small and large amounts of fat and that the delay in emptying liquids of high fat content is associated with redistribution from the distal to proximal regions of the stomach. These findings support the hypothesis that the role of fundic contraction in emptying liquids may be to prime the antral pump.

1 Kelly K. Gastric emptying of liquids and solids: role of proximal and distal stomach. Am $\mathcal{F}$ Physiol 1980; 239: G71-6.

2 Kelly K. Motility of the stomach and gastroduodenal junction In: Johnson LR, ed. Physiology of the gastrointestinal tract. New York: Raven Press, 1981: 393-410.

3 Wilbur BG, Kelly KA, Code CF. Effect of gastric fundectomy on canine gastric electrical and motor activity. Am $\mathcal{F}$ Physio 1974; 226: 1445-9.

4 Wilbur BG, Kelly KA. Effect of proximal gastric, complete gastric and truncal vagotomy on canine gastric electric activity, motility and emptying. Ann Surg 1973; 178: 295302 .

5 Dooley CP, Reznick JB, Valenzuela JE. Variations in gastric and duodenal motility during gastric emptying of liquid meals in humans. Gastroenterology 1984; 87: 1114-9.

6 Houghton LA, Read NW, Heddle R, et al. Motor activity of the gastric antrum, pylorus and duodenum under fasted conditions and after a liquid meal. Gastroenterology 1988; 94: 1276-84.

7 Prove J, Ehrlein H-J. Motor function of gastric antrum and pylorus for evacuation of low and high viscosity meals in pylorus for evacuation of low and high viscosity meals in

8 Heddle R, Dent J, Read NW, et al. Antropyloroduodenal motor responses to intraduodenal lipd infusion in healthy volunteers. Am f P hysiol 1988; 254: G671-9.

9 White CM, Poxon V, Alexander-Williams J. Effects of nutrient liquids on human gastroduodenal motor activity. Gut 1983; 24: 1109-16.

10 Tongas G, Anvari M, Richards D, Dent J, Somers S, Stevenson GW. Relationship of pyloric motility to transpyloric flow in healthy subjects. Gastroenterology 1987; 92: 1673.

11 Azpiroz F, Malagelada J-R. Intestinal control of gastric tone. Am f Physiol 1985; 249: G501-9.

12 Collins PJ, Horowitz M, Cook DJ, Harding PE, Shearman DJC. Gastric emptying in normal subjects - a reproducible technique using a single scintillation camera and computer technique using a single scintillatic

13 Collins PJ, Horowitz M, Shearman DJC, Chatterton BE. Correction for tissue attenuation in radionuclide gastric emptying studies: a comparison of a lateral image method and a geometric mean method. Br 7 Radiol 1984; 57: 68995.

14 Heddle R, Collins PJ, Dent J, et al. The motor mechanisms associated with slowing of the gastric emptying of a solid meal by an intraduodenal lipid infusion. $\tilde{f}$ Gastroenterology and Hepatology 1989; 4: 437-47.

15 Hunt JN, Knox MT. Regulation of gastric emptying. In: Code CF, Heidel W, eds. Handbook of physiology, section 6, vol 4. Alimentary canal. Washington DC: American Physiological Alimentary canal. Washingt

16 Read NW, Houghton LA. Physiology of gastric emptying and pathophysiology of gastroparesis. Gastroenterol Clin North Am 1989; 18: 359-73. 